https://doi.org/10.7559/gestaoedesenvolvimento.2019.384

Data de receção: 15/03/2019 Data de aceitação: 10/07/2019

\title{
O PERFIL DO DIRETOR DA ESCOLA: A IMPORTÂNCIA DAS COMPETÊNCIAS EMOCIONAIS ${ }^{1}$
}

\section{SCHOOL DIRECTOR'S PROFILE: THE IMPORTANCE OF EMOTIONAL SKILLS}

\author{
Célia Ribeiro ${ }^{2}$ orcid.org/0000-0002-1000-6890 \\ Sofia Campos ${ }^{3}$ orcid.org/0000-0002-4696-3537 \\ Maria da Luz Coelho ${ }^{4}$ orcid.org/0000-0002-1428-146X \\ Paulo Almeida Pereira ${ }^{5}$ orcid.org/0000-0002-3941-8274
}

\begin{abstract}
Resumo: O presente estudo teve como objetivo geral conhecer as características da inteligência emocional que norteiam a ação do diretor de escola e que perspetivas têm os professores e os assistentes operacionais relativamente à forma como é levada a cabo a liderança.
\end{abstract}

Foi utilizada uma metodologia de natureza quantitativa, que consistiu na aplicação da Escala de Inteligência Emocional de Moreno (2012) a uma amostra constituída por 131 sujeitos: 3 diretores de escola, 100 professores e 28 assistentes operacionais.

\footnotetext{
${ }^{1}$ Este artigo é parte integrante de um trabalho mais alargado realizado no âmbito de uma dissertação de mestrado em Ciências da Educação - Especialização em Administração e Organização Escolar (UCP - Viseu, 2017), sob a orientação das Professoras Doutoras Célia Ribeiro e Sofia Campos.

2 Doutorada em Psicologia, área de especialidade em Psicologia Pedagógica. Professora Auxiliar da Universidade Católica Portuguesa - Viseu. E-mail: cribeiro@viseu.ucp.pt.

${ }^{3}$ Universidade Católica Portuguesa - Viseu.

${ }^{4}$ Escola Secundária Campos Melo.

5 Professor Auxiliar da Universidade Católica Portuguesa - Viseu - Instituto de Gestão e das Organizações da Saúde. E-mail: ppereira@ viseu.ucp.pt
} 
Os resultados obtidos apresentam os 3 diretores com consciência de que estão na posse das competências emocionais (pessoais e sociais) para o desempenho do cargo. Para os restantes grupos, professores e assistentes operacionais, o expectável nem sempre é verificado, apesar do reconhecimento de inúmeras características de inteligência emocional, os seus diretores não a manifestam sempre.

Palavras-chave: Inteligência Emocional, Gestão Eficaz, Gestão Escolar, Liderança Escolar, Escola de Sucesso.

Abstract: The investigation issue of the current study is the research about the profile of the school head teacher and the importance of emotional skills. Its general purpose is to assess the inherent characteristics to emotional intelligence which guide the actions of the school headteacher and the perspectives that teachers and operational assistants have, regarding the way how his/her management is carried out.

The methodology used was both of qualitative and quantitative nature. The method used to collect quantitative data was a questionnaire with sociodemographic characterization and Emotional Intelligence Scale designed by Moreno, C. (2012).

The qualitative approach was based on the semi - structured interview. The sample comprises 131 subjects -3 school head teachers, 100 teachers and 28 school operational assistants.

The results show that the three head teachers are perfectly aware of their emotional skills (personal and social) to perform their duty, although they have differences in their performance and have diversified styles. In the other groups - teachers and operational assistants - the expected result can't always be confirmed. In spite of the recognition of their innumerable characteristics of emotional intelligence, head teachers do not always meet their expectations.

Keywords: Emotional Intelligence, Effective Management, School Management, School Leadership, School of Success. 


\section{INTRODUÇÃO}

Durante muito tempo, a Inteligência, medida através do Quociente de Inteligência, foi tida como o fator principal na determinação do sucesso do indivíduo. Apesar de importante, os estudos têm demonstrado que a Inteligência não explica integralmente o sucesso, havendo, por isso, outros aspetos determinantes da variação do sucesso individual, especificadamente a Inteligência Emocional (IE). É um facto que a literatura existente tem unido esforços no sentido de confirmar esta posição e uma das orientações mais representativas define a IE como um conjunto de aptidões cognitivas responsáveis pelo processamento da informação emocional, traduzindo-se essas aptidões em capacidades para percecionar, expressar, compreender, regular e utilizar as emoções (Davies, Stankov, \& Robertes, 1998).

$\mathrm{Na}$ verdade, o contributo da IE na vida do ser humano está amplamente documentado, tanto ao nível profissional, como pessoal. A investigação destaca uma relação positiva entre a IE e o desempenho profissional (O`Boyle, Humphrey, Pollack Hawver, \& Story, 2011), a satisfação profissional (Trivellasa, Gerogiannisb, \& Svarnab, 2013), o bem-estar profissional (Garrido \& Pacheco, 2012), e a satisfação geral com a vida e afetos positivos (Gallagher \& Vella-Brodrick, 2008).

A IE vai ganhando espaço no dia-a-dia dos indivíduos, regulando as suas ações, os seus comportamentos e as relações com o outro. Mayer e Salovey (1993) desenvolveram o conceito Inteligência Emocional, explicando-o como a capacidade de perceber, avaliar e expressar de maneira correta as emoções, controlando-as de forma a promover o crescimento emocional e intelectual. "No fundo, razão sem paixão não é mais do que a ruína da alma" (Meyer, 1994, p. 10). Percebe-se, assim, que "uma visão da natureza humana que ignore o poder das emoções é tristemente míope" (Goleman, 2002, p. 20). O mesmo autor atesta que "fomos demasiado longe na ênfase que damos ao valor e importância do puramente racional - aquilo que o QI mede - na vida humana" (p. 20). Não obstante, é impossível separar a racionalidade das emoções, porque são também estas que fundamentam o sentido da eficácia das decisões, a partir do controlo das mesmas (Goleman, 1995). Pelo exposto, o surgimento do conceito de Inteligência Emocional liga, inevitavelmente, 
o domínio/sistema cognitivo ao emocional, resultando na capacidade de fazer com que as emoções atuem a favor do indivíduo que as usa como aliados na escolha de comportamentos que conduzam a bons resultados.

No contexto da organização educacional do século XXI, com uma cultura específica, a escola não se pode abstrair destes conceitos, uma vez que o seu líder está em constante desafio para a promoção do sucesso. $O$ estilo de liderança que cada líder escolhe define a organização escola no seu interior e a imagem que tem no exterior. $\mathrm{O}$ líder de uma escola, em conjunto com os seus pares e toda a comunidade educativa, deve reconhecer a inteligência emocional, que associará à intelectual, num ganho de todos e para todos. Pelo exposto, parece pertinente apresentar as questões lançadas por Goleman que permitem subentender a relação IE com o sucesso individual e organizacional.

\section{A ORGANIZAÇÃO E ADMINISTRAÇÃO EDUCATIVA}

A escola assume-se, na sociedade atual e numa dimensão natural, como local de aprendizagem, tal como referem MacBeath et al. (2005, p.193), “a escola é um local de aprendizagem. (...) Um «local de aprendizagem» é aquele em que há um sistema de crenças partilhado, uma preocupação com o sucesso para todos, um empenho em elevar os níveis e em fazer sempre melhor”.

Para além desta perspetiva, é também considerada um local profissional, como referem os mesmos autores, "a escola é um local profissional se tiver um sistema de recolha de dados e processos de tomada de decisão para melhorar o seu funcionamento. (...) Se desenvolve competências dos professores e possibilita o seu desenvolvimento profissional" (p.195). É, sem dúvida, uma instituição social, com inúmeros objetivos inteiramente expressos, que procura o desenvolvimento das capacidades cognitivas, físicas e afetivas dos alunos.

Centrando a atenção na figura do diretor, é sabido que, ao longo dos anos, o enquadramento jurídico da direção dos estabelecimentos de ensino público foi sofrendo alterações. De acordo com a legislação em vigor - Artigo 20. ${ }^{\circ}$ do Decreto-Lei n. ${ }^{\circ}$ 137/2012, de 2 de julho - o diretor assume uma função central ao ser encarado como representante 
da escola, que tem a cargo as áreas pedagógica, cultural, financeira e patrimonial.

$\mathrm{Na}$ verdade, a escola enquanto organização, é composta por pessoas que a mantêm viva e em funcionamento. Repete-se, amiúde, a expressão organização escolar numa conceção complexa, em que os diversos atores interagem entre si. O verdadeiro entendimento desta organização exige um conhecimento e constante análise do órgão que a lidera. $\mathrm{Na}$ complexa cultura organizacional educativa, todos os intervenientes (professores, assistentes operacionais, alunos) apelam a que seja realizada uma constante reflexão sobre quem lidera a escola, como a lidera, qual o modelo organizacional ideal, quem participa/colabora, como participar, entre outras questões. Neste pressuposto, a gestão educativa, cuja tónica está colocada na liderança de pessoas, terá de ser pautada pelo envolvimento de todos, com as suas especificidades e particularidades, no sentido de um trabalho colaborativo. Segundo Ribeiro (2018, p.108), "Para alcançar o potencial máximo dos recursos humanos de modo a maximizar o seu desempenho é essencial que os indivíduos se sintam motivados", pois só assim as organizações conseguirão obter elevados níveis de desempenho. O sucesso da organização dependerá, inevitavelmente, do investimento de todos, cabendo ao diretor, como líder, liderar todo este processo de forma eficaz. Leia-se Alarcão (2010, p. 138), que destaca de Senge (1990), nas "cinco componentes essenciais de uma organização moderna, inovadora, que se apresenta qualificante para os seus membros" (p.139): a liderança e o equilíbrio pessoal, a existência de modelos mentais, a visão partilhada, a aprendizagem em grupo e o pensamento sistémico.

São vários os autores que destacam a componente humana na liderança. Blanchard et al. (1992, p.81) salientam que "a liderança efectiva não é algo que se faz às pessoas mas algo que se faz com as pessoas". Também para Chiavenato (2003, p.558), a liderança é "uma influência interpessoal exercida numa dada situação e dirigida através do processo de comunicação humana para consecução de um ou mais objectivos específicos". Goleman et al. (2003) numa referência clara às emoções, referem que "se os líderes falharem na tarefa fundamental de encaminhar as emoções na direcção certa, nada do que fizerem 
funcionará bem, ou, pelo menos, não funcionará tão bem como podia ou como devia" (p. 23).

Pelo exposto, conclui-se que os líderes exibem determinados comportamentos e desenvolvem um conjunto de competências, aparentemente ao alcance de todos, que os habilitam para liderar e alcançar os seus objetivos e surgem cada vez mais referenciados como seres emocionais, capazes de influenciar, direta ou indiretamente outros indivíduos com quem trabalham.

\section{DA INTELIGÊNCIA À INTELIGÊNCIA EMOCIONAL E COMPETÊNCIA EMOCIONAL}

Ao longo dos últimos séculos, sobretudo nas sociedades ocidentais, ganhou destaque e foi-se generalizando um ideal — o da Inteligência (Gardner, 1983). O termo inteligência, segundo Almeida, Guisande e Ferreira (2009), é utilizado amiúde sem nos questionarmos sobre o seu real significado mas, ao longo dos tempos, têm sido grandes os esforços na procura de um significado consensual.

Para os psicólogos, a definição de inteligência apresenta-se como um desafio, como refere Feldman (2001), mas pode dizer-se que, para muitos, a inteligência é a capacidade para compreender o mundo, pensar racionalmente e utilizar eficazmente recursos quando confrontado com desafios. No entanto, a noção de inteligência significa coisas diferentes para diferentes pessoas e, como se denota em Almeida (1988), é, apesar de toda a controvérsia que tem gerado no seio de diferentes grupos profissionais e da própria opinião pública, objeto de um largo número de investigações, permanecendo como um dos critérios de análise do comportamento humano com imensas aplicações, sendo bem significativas na vida de cada pessoa.

Surge, então, o fator emocional intimamente ligado a esta definição. Ainda que não conheça um lugar de destaque, segundo LeDoux (2000), a emoção está intimamente ligada à evolução da espécie humana, permitindo perceber o que fomos, o que somos e para onde caminhamos. Ao falar da emoção, Damásio (1995) mostra que é impossível separá-la da razão, posição corroborada por Goleman (1995), que interpreta a emoção como um sentimento em que os raciocínios que dela derivam 
são estados psicológicos e também biológicos orientados para a ação. Neste sentido, coloca-se em evidência uma energia emocional como fator que irá determinar comportamentos e decisões. Outros autores têm vindo a dar contributos importantes em torno da emoção: é o caso de Filliozart (1997), que a retrata da seguinte forma: “a emoção é um movimento em direção ao exterior, um impulso que nasce no interior de nós próprios e fala ao que nos rodeia, uma sensação que nos diz quem somos e nos coloca em relação com o mundo. (...) A vida emocional está estreitamente ligada à vida relacional" (Filliozart 1997, p.28).

São vários os contributos para uma discussão em torno do conceito de emoção. Leia-se, por exemplo, "a emoção torna o pensamento mais inteligente, e a inteligência permite pensar e usar as emoções de modo mais apurado" (Cunha et al., 2010, p. 252). Os indivíduos emocionalmente inteligentes "são os que usam a razão para compreender as emoções (as suas e as dos outros) e lidar com elas, e que recorrem às emoções para interpretar a envolvente e tomar decisões mais inteligentes" (Cunha et al., 2010, p. 252).

De acordo com Goleman, "as nossas emoções guiam-nos quando temos de enfrentar situações e tarefas demasiado importantes para serem deixadas apenas a cargo do intelecto". Deste modo, "para o melhor e para o pior, a inteligência pode não ter o mínimo valor quando as emoções falham" (1997, p. 22) e as emoções conduzem à acção" (Goleman, 1997, p.23).

A inteligência emocional surge, como dizem Almeida, Guisande e Ferreira (2009), como um conjunto de capacidades mentais que facilitam o reconhecimento dos padrões, das emoções e consequente capacidade para raciocinar e resolver problemas, dando corpo a uma nova modalidade de crescimento intelectual. Desta forma, à questão que se levanta tantas vezes sobre que fatores estão em jogo quando, por exemplo, pessoas a quem foi atribuído um teste de QI elevado falham onde outras com um QI mais modesto se portam surpreendentemente bem, Goleman (2002) responde que a diferença reside frequentemente nas capacidades a que ele chama de inteligência emocional, que inclui o autocontrolo, o zelo e a persistência, bem como a capacidade de cada um se motivar. 
Surge, então, a Competência Emocional, "uma capacidade adquirida, baseada na IE, que resulta num desempenho destacado no trabalho" (Goleman, 1995, p. 38). A IE irá determinar o potencial de um indivíduo para aprender as habilidades práticas que estão baseadas nos conceitos da autoperceção, da motivação, da autorregulação, da empatia e da aptidão natural para os relacionamentos.

Continuando a centrar a atenção em Goleman, cabe agora a sua definição do conceito de Competência Emocional, tal como assinala Notas (1999, p. 341), que considera que a expressão Competência Emocional inclui tanto competências sociais como emocionais, e defende que "uma Competência Emocional é uma capacidade apreendida, baseada na Inteligência Emocional, que resulta num desempenho extraordinário no trabalho". Nesta linha, assume que "a nossa Inteligência Emocional determina o nosso potencial para aprender as aptidões práticas que se baseiam em cinco elementos: Autoconsciência, Motivação, Autodomínio, Empatia e Talento nas Relações. A nossa Competência Emocional mostra até que ponto, traduzimos esse potencial nas capacidades profissionais" (Goleman, 1999, p. 33).

É precisamente aqui que é feita a abordagem da aplicação e observação das capacidades que inscrevem a Inteligência Emocional em contextos de trabalho. É inegável o aumento do interesse, nas mais diversas áreas profissionais, pelo mundo das emoções, sem descurar a gestão que é feita das mesmas (Rebelo e Martins, 2015). Em Bar-On e Parker (2000) pode ler-se "hoje em dia, os locais de trabalho consideram que a IE é mais valiosa do que as competências técnicas e cognitivas." (p.149). Neste sentido, Goleman (1999) escreveu a respeito da importância do reconhecimento da própria vida emocional, regulando os próprios sentimentos, compreendendo as emoções dos outros, sendo capaz de trabalhar com os outros e ter empatia por eles. O seu modelo da IE dispõe, portanto, de um conjunto de competências e capacidades emocionais que motivam o indivíduo para o sucesso das exigências que a sociedade lhe impõe. As competências ligadas à IE reúnem-se em quatro grandes domínios: Autoconsciência, Autodomínio, Consciência Social e Gestão das Relações, que garantem uma teia de competências emocionais capazes de gerir a vida emocional com inteligência. 


\section{INTELIGÊNCIA EMOCIONAL E LIDERANÇA NA DIREÇÃO DE ESCOLAS}

Atualmente sabe-se que a liderança é considerada por muitos autores como um elemento verdadeiramente capaz de fazer a diferença, não só nas organizações em geral, mas, acima de tudo nas organizações educativas. Garcia (2001) designa o novo líder por pós-convencional, dizendo que tem "o especial valor de pensar de forma diferente, de decidir desenvolver-se como pessoas, de libertar energia criativa nos seus colaboradores, de contribuir para a criação de uma sociedade mais solidária e de criar espaços de diálogo para a verdadeira construção de valores partilhados (Garcia, 2001, p. 1). Esta ótica surge enquadrada nas recentes políticas sobre esta liderança, quer no contexto das organizações em geral, quer no das organizações educativas, em particular.

Goleman (1995) apresenta o seu próprio conceito de liderança: “O papel emocional do líder é primal - isto é, vem em primeiro lugar - em dois sentidos. É o primeiro acto de liderança e, ao mesmo tempo, é o mais importante" (Goleman, Boyatzis, \& Mckee, 2002, p. 25). Assim, é percetível que estes autores apresentam como ideal uma escola que possa pautar-se por valores, sendo que despertar os valores parece ser a tarefa mais importante de todos os líderes.

Na esfera da Administração e Gestão Escolar, a liderança assume, assim, um papel fulcral, já que ela está intimamente relacionada com a gestão das emoções. A este propósito, Goleman e colaboradores (2007, p. 59) destacam que “os grandes líderes são pessoas muito mobilizadoras, pessoas que despertam o nosso entusiasmo e estimulam o que temos de melhor". Para além disto, analisam o líder como um manipulador de si e do outro para alcançar os seus fins, acrescentando que "os grandes líderes são pessoas que sabem manipular as emoções" (Goleman et al., 2007, p.59). Daqui se depreende que o líder, leia-se também o "diretor de escola", tem como objetivo dirigir as emoções de todos a fim de criar uma rede de relações bem-sucedidas. Assim sendo, IE e liderança trilham os mesmos caminhos no que à organização escolar diz respeito. Reforce-se aqui o preconizado por Goleman (1998), ao destacar que "qualquer homem de negócios conhece uma história de um 
executivo muito inteligente e muito capacitado que foi promovido a uma posição de liderança e falhou". De igual forma, "também se conhecem histórias de pessoas com sólidas - mas não extraordinárias -capacidades intelectuais e técnicas que foram promovidas a uma posição similar e que tiveram sucesso" (1998, p. 93). A literatura existente facilmente confirma que identificar indivíduos com as capacidades certas para serem líderes eficazes de uma organização/instituição, estabelecimento de ensino, não se consegue através do reconhecimento de capacidades intelectuais extraordinárias. Reforça, sim, "a necessidade dos gestores/líderes possuírem competências desenvolvidas e que se adequem ao papel ou papéis que estão a desempenhar"(Lopes e Baioa, 2011, p.26).

\section{METODOLOGIA DA INVESTIGAÇÃO}

\subsection{Objetivos}

Tendo como objetivo geral "conhecer as características da inteligência emocional que norteiam a ação do diretor de escola e que perspetivas têm os professores e os assistentes operacionais relativamente à forma como é levada a cabo a liderança”, foram definidos quatro objetivos específicos: verificar se a atuação de um diretor de escola é orientada por características de inteligência emocional, na perspetiva dos diretores, professores e assistentes operacionais; perceber como as características da IE se encontram presentes na ação do diretor e se vão ao encontro das expectativas dos professores e assistentes operacionais; compreender a perspetiva dos professores e assistentes operacionais relativamente à forma como é levada a cabo a gestão; refletir sobre a importância das competências emocionais no sucesso da liderança.

\subsection{Tipologia da Investigação}

Como metodologia utilizada, considerou-se mais adequado o modelo quantitativo, descritivo, transversal e correlacional, que visa colher dados observáveis e quantificáveis, baseando-se na observação de factos objetivos, de fenómenos e acontecimentos que ocorrem, independentemente do investigar (Fortin, 2013), sendo posteriormente 
descritos de forma a especificar as características e os perfis de pessoas submetidas a análise (Freixo, 2009). Para o mesmo autor, importa avaliar a existência de uma correlação entre as categorias em estudo, resultante dos seus comportamentos.

\subsection{Caracterização da amostra}

Os participantes deste estudo estão inseridos em 3 escolas situadas na zona centro do país. Os diretores possuem uma vasta experiência de chefia e já experienciaram diferentes modelos de organização e gestão das escolas. As suas idades são semelhantes. Relativamente aos professores das escolas, são caracterizados de acordo com a idade, o grupo disciplinar e o vínculo que possuem. Estes critérios prendem-se com a necessidade de conhecerem a instituição em causa, os diferentes órgãos e modelos de direção que já conheceram e o vínculo e grau de envolvimento que possuem com este estabelecimento em concreto. Finalmente, o corpo não docente inquirido é, igualmente, o das escolas.

Em suma, o conjunto que constituiu a amostra deste estudo é composto por $\mathbf{3}$ diretores de escola, $\mathbf{1 0 0}$ professores das escolas que dirigem e 28 assistentes operacionais das mesmas, perfazendo um total de 131 inquiridos.

\subsection{Instrumento de recolha de dados}

$\mathrm{O}$ instrumento aplicado encontra-se dividido em duas partes, a primeira parte tem como objetivo recolher dados biográficos e a situação profissional dos sujeitos participantes na investigação, caracterizando a amostra de acordo com variáveis como o género e idade, estado civil, variáveis profissionais propriamente ditas, como as habilitações académicas, formação pedagógica, anos de serviço total e na instituição, vínculo e grupo de docência. Cada questionário apresentava especificidades, de acordo com o grupo de participante (docentes, assistentes operacionais e diretores),

A segunda parte do instrumento era constituída pela Escala de Inteligência Emocional de Moreno (2012). Esta escala, enquanto instrumento de autoavaliação e de recolha, foi construída a partir dos domínios da Inteligência Emocional e Competências associadas, 
preconizadas por Goleman e colaboradores (2007), adaptada por Moreno (2012).

A escala utilizada contém 32 questões que versam os vários domínios da IE e competências associadas: competências pessoais (autoconsciência e autogestão) e competências sociais (consciência social e gestão das relações). Trata-se de uma escala tipo Likert com 5 opções de resposta: sendo o 1 o que corresponde a Nunca, o 2 a Raramente, o 3 a Poucas Vezes, o 4 a Quase Sempre e o 5 a Sempre.

Assim, do item 1 ao item 16 surgem as competências individuais e do item 17 ao item 32, as competências sociais. Numa análise detalhada, o primeiro grupo de oito questões centra a sua atenção na competência pessoal da autoconsciência, em que se deseja que cada um dos inquiridos dos vários grupos avalie o diretor da sua organização escolar quanto à autoconsciência emocional, isto é, à sua capacidade de reconhecer as emoções e as suas forças e limites. A avaliação da subescala competência da autogestão está presente nos itens 9 a 16 . Neste sentido, elencaram-se perguntas que visaram aferir o autodomínio emocional do diretor, traduzido nos conceitos de transparência, capacidade de adaptação, de iniciativa e otimismo.

Relativamente às competências sociais, questionaram-se os diferentes inquiridos, no sentido de se perceberem as perceções sobre se o diretor fruiu de uma consciência social assente na empatia, espírito de serviço e, finalmente, se é capaz de gerir as relações através de um avivar da consciência organizacional. Por fim, pretendeu-se entender se o diretor, na subescala gestão das relações, é um catalisador da mudança e influência ao nível da liderança, se consegue gerir conflitos, criar laços, cultivar e manter redes de relações.

Nesta escala de Moreno (2012), a validação estatística, no geral, e das quatro subescalas, foi feita através do cálculo do Alfa de Cronbach, alcançando-se valores bastante satisfatórios. A escala utilizada possui elevados índices de consistência interna, o que se traduz numa fiabilidade muito satisfatória. A fiabilidade de uma medida acusa a capacidade desta ser consistente, sendo que a consistência interna varia entre zero e um. 


\section{Quadro 1}

Consistência interna do instrumento de recolha de dados

\begin{tabular}{|c|c|c|c|c|}
\hline $\boldsymbol{\alpha}$ & $\boldsymbol{\alpha}$ & $\boldsymbol{\alpha}$ & $\boldsymbol{\alpha}$ Consciência & $\boldsymbol{\alpha}$ Gestão das \\
Total & Autoconsciência & Autogestão & Social & Rẽos \\
\hline 0.949 & 0.810 & 0.719 & 0.849 & 0.937 \\
\hline
\end{tabular}

Como se pode verificar através da análise do valor de $\boldsymbol{\alpha}$ encontrado, são valores, quase na sua totalidade, reveladores de uma boa consistência interna. A subescala autogestão foi a que apresentou um valor de $\boldsymbol{\alpha}$ mais baixo $(0,719)$. Contudo, admite-se que se trata de um valor aceitável, que não põe em causa a qualidade do instrumento de recolha de dados utilizado nesta investigação.

\section{RESULTADOS}

Das respostas dos 3 grupos aos questionários, obtiveram-se como mais relevantes os resultados que se apresentam de seguida:

Da análise dos dados à questão "É capaz de ler as suas próprias emoções", os 3 diretores inquiridos respondem que sempre o fazem, posição não corroborada pelos professores e assistentes operacionais.

Quando questionados sobre se o diretor "Pondera as consequências éticas e morais das suas decisões", os próprios respondem que sempre, não indo, mais uma vez, ao encontro das perceções dos seus dirigidos. Aqui, a maioria dos professores afirma que, a seu ver, quase sempre ou sempre fazem essa ponderação. Do total de 97 inquiridos, apenas 26 respondem poucas vezes. Nos assistentes operacionais, a opinião está dividida entre o raramente e poucas vezes ponderam consequências das ações, com dez inquiridos nestas respostas, enquanto os restantes 18 manifestam opinião mais favorável, dizendo que quase sempre ou mesmo sempre.

$\mathrm{Na}$ terceira questão colocada, "Enfatiza as vantagens de ter um sentido de missão comum na instituição", os 3 diretores apresentam posições díspares, já que 2 dizem que sempre o fazem e apenas um refere que quase sempre. No grupo dos professores, a maioria é de opinião que os seus diretores quase sempre ou sempre enfatizam o sentido de missão, ao contrário de 16 que afirmam raramente ou poucas 
vezes o fazerem. Embora os assistentes operacionais estejam divididos sobre este assunto, no entanto, a tendência é positiva na medida em que 20 atestam no sentido do quase sempre e sempre e 8 referem que raramente ou poucas vezes veem essa capacidade nos diretores.

Quando questionados sobre se "Reflete sobre as críticas que lhe são feitas e verifica se são ou não adequadas", os 3 diretores são unânimes em considerar que o fazem. Por outro lado, no grupo dos professores, existe um número bastante significativo de inquiridos, 46, a apresentar respostas insatisfatórias, havendo 14 sujeitos desta categoria para quem os seus diretores poucas vezes fazem essa reflexão. Ainda assim, na sua maioria, entendem que quase sempre ou sempre os seus diretores refletem sobre as críticas feitas. Passando ao grupo dos assistentes operacionais, as posições surgem invertidas, na medida em que a maioria avalia de forma menos positiva os seus diretores. São 15 os operacionais que tendem para nunca, raramente e poucas vezes verem concretizado esse exercício de reflexão.

Quanto à questão "Tem consciência das suas forças e limites", apenas um diretor refere que tem sempre essa consciência, enquanto 2 dizem estar quase sempre conscientes dessa realidade. Relativamente ao grupo dos professores, 71 consideram que os diretores das escolas a que pertencem têm consciência das próprias forças e limites. No tocante aos assistentes operacionais, a maioria também tem a mesma opinião do grupo anterior, pois 18 respondem nos níveis positivos.

Quando questionados sobre a ação do diretor, mais concretamente se "Está ausente quando precisam dele", os 3 diretores inquiridos respondem que nunca estão ausentes. Relativamente aos professores, da totalidade dos inquiridos, 40 respondem que o seu diretor nunca está ausente; 37 afirmam que raramente está ausente e 12 dizem estar poucas vezes. Quanto aos assistentes operacionais, para 7 inquiridos o diretor nunca está ausente, sendo 15 os que afirmam que esta situação raramente acontece.

À necessidade de saber se o diretor "Atua apenas quando os problemas se tornam manifestos", os 3 diretores respondem em sintonia que nunca o fazem. Já o grupo dos professores surge dividido, pois 16 inquiridos dizem que nunca atua desta forma; 42 referem que raramente agem neste sentido e 32 indicam poucas vezes. Passando aos 
assistentes operacionais, apenas 18 declaram que o seu diretor nunca ou raramente atua de acordo com o indicado na questão.

Quando questionados sobre se o diretor "Controla os impulsos e as emoções negativas", 2 dizem que sempre o fazem e um quase sempre. No grupo dos professores, a maioria afirma no sentido mais positivo, com 59 a declarar que quase sempre e sempre controlam. No sentido contrário, 13 referem que os diretores nunca e raramente controlam os impulsos, e 27 estão convictos de que poucas vezes conseguem levar a cabo essa capacidade. Relativamente aos assistentes operacionais, a maioria considera que raramente e poucas vezes veem o diretor a controlar os seus impulsos e emoções. Por outro lado, 12 destacam que quase sempre e sempre reconheceram essa capacidade.

À pergunta "Inspira otimismo, confiança e transparência", 2 diretores consideram que alcançam sempre essa inspiração no outro e um refere que consegue fazê-lo quase sempre. A posição dos professores surge dividida, sendo que a maioria encontra no diretor essas características, com 34 a responder quase sempre e 33 sempre. Nos assistentes operacionais, a maioria encontra otimismo, confiança e transparência no diretor da sua escola, com 20 a mostrar que quase sempre e sempre aconteceu.

$\mathrm{Na}$ questão que pretende aferir se o diretor "Trata os outros como um indivíduo e não apenas como mais um membro do grupo", um diretor refere que quase sempre e 2 que sempre o fazem. Nos professores, as opiniões são diferentes, já que se distribuem por todas as questões da tabela. Assim, 67, a maioria, considera que quase sempre e sempre são tratados como um indivíduo. Observando os assistentes operacionais, as opiniões também divergem, mas a maioria inclina-se para respostas menos favoráveis, no sentido em que 14 dizem que nunca, raramente ou poucas vezes foram tratados como um indivíduo.

Colocada a pergunta "Exprime satisfação quando os outros correspondem às expectativas", os 3 diretores mostram que sempre denunciaram essa satisfação. Quanto aos professores, a maioria também o considera, com 75 a apresentar uma opinião favorável aos diretores, afirmando que quase sempre e sempre encontraram a expressão da satisfação. Ainda assim, são 25 os professores que respondem poucas vezes e raramente. Nos assistentes operacionais, 21 possuem uma ideia 
positiva do diretor no tocante a esta questão, pois afiançam que quase sempre e sempre expressaram satisfação na situação descrita.

Relativamente à questão "Ajuda os outros a desenvolver os seus pontos fortes", os 3 diretores não estão em consonância, já que 2 consideram que sempre o fazem e um que quase sempre. No grupo dos professores, surgem respostas muito variadas, ainda que 64, a maioria, refira que quase sempre e sempre sentiram a ajuda. Em relação aos assistentes operacionais, verifica-se uma situação semelhante, sendo 17 os que referem quase sempre e sempre receberam a ajuda no desenvolvimento dos pontos fortes.

Na questão "Reconhece e satisfaz as necessidades da comunidade educativa", 2 respondem que sempre e um quase sempre o faz. O grupo dos professores divide-se nas respostas. A maioria, com 74 sujeitos, possui uma visão positiva. Assim, 41 consideram que quase sempre e 33 sempre encontraram no diretor esse reconhecimento e satisfação. Contudo, há 19 elementos a referir que poucas vezes tal sucedeu. Passando ao grupo dos assistentes operacionais, 23 atestam que quase sempre e sempre receberam do diretor as atitudes referenciadas, havendo 5 a responder poucas vezes.

Quando questionados sobre se o diretor "Lidera e motiva os colaboradores para obter sucesso", os próprios dizem, na totalidade, que sempre. Centrando a atenção no grupo dos professores, estes divergem nas opiniões. Assim, 66, a maioria, manifestam que sentem a liderança e motivação enunciada. No entanto, há um número considerável que tem outra opinião, pois para 24 poucas vezes tal situação se verifica. Passando agora aos assistentes operacionais, 21 demonstram uma opinião favorável.

No tocante à pergunta "Usa métodos de liderança que são satisfatórios", 2 diretores afirmam que quase sempre e um sempre os usa. Do lado dos professores, as respostas continuam diversificadas, com a maioria a entender no nível positivo, pois são 66 a afirmar quase sempre e sempre. Nos assistentes operacionais, o quase sempre e o sempre é selecionado por 16 elementos.

Sobre a afirmação "Resolve eficazmente desacordos e disputas", os 3 diretores sentem que o fazem quase sempre. Analisando os dados recolhidos dos professores, a maioria, 61 elementos desta categoria, 
entende que existe uma boa resolução. Menos otimistas são os 26 elementos para quem o diretor resolve poucas vezes de forma eficaz os problemas. Em relação aos assistentes operacionais, num ponto de vista mais afirmativo estão 13 inquiridos a responder quase sempre e cinco sempre.

\section{DISCUSSÃO DOS RESULTADOS}

Considerando os objetivos definidos, apresentamos de seguida a discussão dos resultados.

Verificar se a atuação de um diretor de escola é orientada por características de inteligência emocional, na perspetiva dos diretores, professores e assistentes operacionais.

$\mathrm{Na}$ autoconsciência dos diretores, pode ler-se que os 3 se consideram sempre capazes de ler as suas emoções e de ponderar as consequências éticas e morais das suas decisões. Os 3 líderes refletem sempre sobre as críticas que lhes são feitas, na tentativa de melhorar. Para eles, o reconhecimento dos valores e objetivos são uma constante e demonstram, sempre, uma preocupação de aperfeiçoamento das competências pessoais, inspirando confiança e transparência. De facto, também em Dias (2014, p.91), "a ética e as organizações, tornam-se indissociáveis estando diretamente ligadas a relações, a comportamentos".

De acordo com Garcia (2001), estes líderes precisam mesmo de "desenvolver-se como pessoas, de libertar energia criativa nos seus colaboradores, de contribuir para a criação de uma sociedade mais solidária" (p.1). Também Damásio (2011) ajuda a entender as suas decisões diárias ao referir que são as emoções que ajudam o ser humano em geral e, obviamente, os diretores de escola, a prever um futuro e até a planear as ações que vão encetar. Weisinger (1998, citado por Nikolaou \& Tsaousis, 2002) sugere mesmo que existe uma relação direta entre inteligência emocional e sucesso no trabalho.

Refira-se, também, a teoria de Goleman et al. (2002) sobre as pessoas autoconscientes: "são realistas - nem demasiado críticas em relação a si próprias nem ingenuamente confiantes" (p. 60). Mais ainda: "alguém 
que possua uma elevada autoconsciência sabe onde está colocada e porquê" (Goleman, 1998, p. 96). É no contexto deste realismo que, questionados sobre o controlo das emoções negativas ou o facto de inspirarem confiança e otimismo, um dos diretores julga que o faz, mas apenas quase sempre.

A autoconsciência reflete-se também na forma como o sujeito lida com as suas próprias fraquezas. Na mesma obra, Goleman (1998) afirma que "as pessoas autoconscientes conhecem - e estão confortáveis a falar sobre - as suas limitações e fraquezas, e frequentemente demonstram uma sede de crítica construtiva" (p. 96). Do exposto pelos 3 inquiridos, ressalta que os líderes autoconscientes "conhecem os seus valores, objectivos e sonhos. Sabem para onde vão e porquê" (Goleman et al., 2002, p. 60).

Ao colocar a tónica no ponto de vista e nas perspetivas dos professores e dos assistentes operacionais, pode pensar-se em Goleman e colaboradores (2002), ao afirmarem que os líderes "geram uma atmosfera de colegialidade amistosa e são modelos de respeito pelos outros, de espírito de ajuda e de aptidão para a cooperação (...), atraem os outros para uma participação activa" (p. 276). De facto, tanto os professores como os assistentes operacionais apresentam uma visão que não se identifica completamente com o que foi dito até aqui. Olhando para a apresentação dos resultados dos questionários, vê-se que 30 professores consideram que o seu diretor raramente ou poucas vezes apresenta a habilidade de ler as suas emoções. A quase totalidade dos assistentes operacionais segue a mesma linha de pensamento. $\mathrm{O}$ mesmo acontece quando se pretende conhecer a capacidade de ponderação sobre as consequências éticas e morais das decisões do diretor. Também aqui se percebe uma divergência relativamente ao grupo dos diretores e aos outros 2 grupos. A posição mais significativa encontra-se na maioria dos professores que não veem este comportamento de líder no seu diretor.

O controlo dos impulsos e das emoções assume-se como uma característica imprescindível da inteligência emocional, pelo que importa verificar as divergências de posições nos 3 grupos. Os assistentes operacionais possuem uma visão menos positiva do diretor, pois a maioria considera que raramente e poucas vezes percebem esse controlo. 
Nos professores, a maioria tem uma posição mais positiva, ainda que 40 vejam um desempenho negativo.

\section{Perceber como as características da Inteligência Emocional se encontram presentes na ação do diretor e se vão ao encontro das expectativas dos professores e assistentes operacionais.}

Para responder a este objetivo da investigação, importa recordar mais uma vez as características das competências emocionais de Goleman (2007). Obviamente, há que ter em mente a capacidade de realização e iniciativa (presentes na autogestão), a consciência organizacional, o espírito de serviço (presentes na consciência social), o espírito de equipa e colaboração, a gestão de conflitos, capacidade para desenvolver os outros (presentes na gestão da relação), plenamente refletidos nos questionários deste estudo.

Ao pensar-se na autogestão apresentada por Goleman (2007), os 3 diretores consideram que atuam no momento certo, estando presentes sempre que precisam dele. Ainda assim, 2 assumem que não investem sempre o seu tempo a ajudar os docentes, apesar de todos se preocuparem sempre em fazer mais e melhor pela instituição. Nas suas atuações, pode ler-se Goleman (2000) no que à motivação diz respeito e à forma como esta é usada na aplicação das competências emocionais de cada um. De acordo com este autor, existe uma vontade de vencer, de triunfar, de lutar e conquistar, bem patentes nas afirmações dos diretores em causa. Também Goleman e colaboradores (2002) referem as emoções como "a forma do cérebro nos alertar para algo de urgente e nos proporcionar um plano de ação imediata: lutar, fugir, ficar imóvel" (p. 47). Sem dúvida que, neste passo, não se pode deixar de citar Goleman (1995), quando aborda a arte do relacionamento, que contempla a capacidade de trabalhar em grupo. Mais uma vez, é Garcia (2001) que sustenta estas posições ao expor que os líderes devem "criar espaços de diálogo para a verdadeira construção de valores partilhados" (p. 1). Confrontados com a necessidade de saber se é eficaz no atendimento das necessidades dos outros em relação ao trabalho, se compreende as suas perspetivas, se exprimem satisfação perante o outro, os 3 diretores afirmam que sempre se apresentam dessa forma. A mesma avaliação fazem de si, quando confrontados com a questão de liderarem 


\section{Célia Ribeiro, Sofia Campos, Maria da Luz Coelho e Paulo Pereira}

e motivarem para o sucesso ou de desenvolverem estratégias de motivação para alcançar os objetivos.

Passando aos 2 grupos restantes, sobre as mesmas matérias, as posições de professores e assistentes operacionais corroboram as dos seus diretores. Sobre a liderança e motivação para o sucesso, a maioria dos professores e dos assistentes operacionais apresentam uma opinião positiva. No entanto, alguns ainda veiculam posições negativas. A mesma tendência apresentam na questão relativa ao atendimento das necessidades dos outros em relação ao trabalho, relativamente à expressão da satisfação perante o outro ou no tocante ao espírito de equipa criado. Apesar de se encontrar a maior parte dos inquiridos a responder positivamente, há ainda um número significativo de respostas menos satisfatórias.

Ao discutir os resultados, percebe-se que o autoconceito dos diretores sobre as suas competências não é totalmente corroborado pelos professores nem pelos assistentes operacionais. A imagem que os líderes têm de si não é a mesma que os liderados revelam nas respostas apresentadas. Apesar de uma maioria que se mostra em sintonia, há uma percentagem elevada em ambos os grupos que responde em sentido oposto ao dos diretores. A relação que os diretores mantêm com professores e assistentes operacionais não é sentida no nível muito bom. Veja-se aqui que, para um grupo de 23 professores e 5 assistentes operacionais, os seus diretores poucas vezes compreendem a perspetiva dos outros e se interessam pelos seus problemas. Já os líderes afirmam que o fazem sempre. Situação semelhante acontece quando questionados sobre o desenvolvimento de estratégias de motivação de forma a alcançar novos objetivos não esperados. Os 3 diretores respondem que sempre o fazem, mas os professores e os assistentes operacionais dizem que poucas vezes têm essa perceção. Sobre os diferentes pontos de vista apresentados, importa citar Wall (2007), que vem destacar a importância das relações na liderança. Para este autor, o tempo que o líder usa para criar a ideia de que "estamos todos juntos" (p. 26) é fundamental para o sucesso. É pois a inteligência emocional, segundo o mesmo autor, que distingue desempenhos bons de outros pouco interessantes, posição corroborada por Cunha e Rego (2005), que valorizam nos líderes emocionalmente inteligentes a habilidade comunicativa, ajustando-a às 
circunstâncias e tendo como objetivo sensibilizar o outro. Desta forma, evitam conflitos negativos e explosões emocionais. Neste momento da discussão, importa recordar Rego (1998), ao apresentar a ideia de que ao sintonizar as emoções dos colaboradores, os líderes ficam mais capacitados para motivá-los e entusiasmá-los.

Continuando a discussão, veem-se os líderes divididos relativamente ao facto de poderem cultivar e manter redes de relações, pois surge um diretor com uma resposta mais moderada, considerando que quase sempre o faz. A maioria dos outros 2 grupos, professores e assistentes operacionais, apresenta respostas positivas, contra um número considerável de respostas negativas, nomeadamente no seio dos professores.

$\mathrm{Na}$ realidade, estes líderes estão enquadrados no que Goleman e colaboradores (2002) perseguem relativamente à gestão das relações. Segundo estes autores, o líder terá de conhecer e ser capaz de lidar com as emoções daqueles com quem atua, no sentido de ser capaz de desenvolver o outro. Estes diretores estão alinhados com a ideia dos autores referidos, pois "mostram um interesse genuíno relativamente às pessoas que orientam" (p. 276). Para além disso, mostram competências na gestão de conflitos ao "trazerem os conflitos à luz do dia (...) e, depois, canalizam a energia para um ideal comum” (p. 276).

\section{Compreender a perspetiva dos professores e assistentes} operacionais relativamente à forma como é levada a cabo a liderança.

Relativamente a este objetivo, importa trazer à discussão a empatia (consciência social), o criar laços e a capacidade de desenvolver os outros (gestão da relação). Quando se confronta o ponto de vista dos diretores com o dos professores e dos assistentes operacionais, concluise que o conceito que estes possuem da pessoa e da atuação dos diretores não vai ao encontro dos julgamentos que os mesmos fazem de si próprios. Os 2 grupos liderados esperam que os seus líderes ajam em conformidade com as expectativas de cada um, indo ao encontro do que preconizam para a instituição onde trabalham. Pensando no ponto de vista dos professores e dos assistentes operacionais, Goleman e colaboradores (2002) apresentam o otimismo como forma de interpretar 
as palavras dos diretores. Para os autores, esta capacidade permite que os líderes suportem bem os conflitos, descubram as oportunidades, em vez das ameaças e dificuldades que possam encontrar, encaram-se a si e aos outros de forma positiva (Goleman et al., 2002). No entanto, esta não parece ser a perspetiva dos outros intervenientes neste estudo. Wall (2007) expõe um líder emocionalmente inteligente como aquele que lidera através da influência, sendo que a sua ação visa criar uma cultura de participação e de reconhecimento. Cunha e colaboradores (2010) vêm na mesma orientação ao salientar que estes líderes têm à sua frente uma pessoa, e não equipamentos. Neste sentido, quando confrontados com o facto de tratarem os outros como um indivíduo e não apenas como um membro do grupo, 2 diretores dizem fazê-lo sempre e um quase sempre. A maioria dos professores segue a mesma linha, ainda que o número dos que têm opinião contrária seja elevado. Nos assistentes operacionais verifica-se o oposto, pois a maioria diz sentir-se tratado como mais um membro no grupo, contra os restantes que se veem como um indivíduo.

Mais uma vez, Goleman e colaboradores (2002) vêm explicar que a avaliação que o líder faz de si permite-lhe conhecer as suas forças e também os seus limites, tal como a autoconfiança lhe permite estar na posse de uma boa noção do seu valor e das suas capacidades. Esta ideia, que vem corroborada pelos diretores, não é unânime nos professores e assistentes operacionais. À discussão trazem-se Davies, Stankov e Robertes (1998), quando apresentam a inteligência emocional como um conjunto de aptidões necessárias para o processamento da informação emocional, traduzindo-as em capacidades da pessoa para percecionar, expressar, compreender, regular e utilizar as emoções. Estas capacidades estão assumidas nas respostas dos diretores, ao referirem que exprimem satisfação quando os outros correspondem às expectativas. Ainda que a maioria concorde, existem professores e assistentes operacionais para quem poucas vezes a expressão da satisfação é demonstrada.

$\mathrm{Na}$ explanação das características dos líderes emocionalmente inteligentes, importa destacar Cunha e Rego (2005, p. 140), quando referem que os líderes emocionalmente inteligentes "estão mais habilitados a variar as formas comunicacionais de modo ajustado às circunstâncias, para actuar de acordo com a oportunidade, para articular uma visão e utilizar um discurso sensibilizador dos seus alvos”. 


\section{Refletir sobre a importância das competências emocionais no sucesso da liderança.}

Uma reflexão sobre a importância das competências emocionais no sucesso da liderança pressupõe que entrem em discussão todas as competências individuais e sociais preconizadas por Goleman e seus colaboradores (2007). A literatura existente facilmente confirma que identificar indivíduos com as capacidades certas para serem líderes eficazes de uma organização/instituição, estabelecimento de ensino, não se consegue através do reconhecimento de capacidades intelectuais extraordinárias.

Observando as respostas aos questionários, os 3 diretores assumem que falam com entusiasmo sobre o que precisa de ser melhorado. Contudo, sobre a ajuda aos outros no desenvolvimento dos pontos fortes, na satisfação das necessidades da comunidade educativa, ou na procura de novas orientações e de novos caminhos, não há acordo pleno, pois um deles considera que o faz "quase sempre", ao contrário do "sempre" dos outros 2. Os restantes grupos revelam uma tendência positiva, na maioria, assistindo-se a um grupo relativamente elevado de inquiridos com opiniões negativas.

Continuando na mesma linha de discussão, existe uma forte preocupação na gestão das situações e na capacidade de decisão dos diretores, manifestada tanto por professores, como pelos assistentes operacionais. Por isso, quando questionado sobre se usam métodos de liderança que consideram satisfatórios, 2 deles pensam que quase sempre o fazem, apenas um diz que sempre os usa e a maioria dos professores e dos assistentes operacionais pensam e respondem da mesma forma.

Conhecer as características da inteligência emocional que norteiam a ação do diretor de escola e que perspetivas têm os professores e assistentes operacionais relativamente à forma como é levada a cabo a liderança.

Depois de respondidos os objetivos específicos deste estudo, pretende-se, de seguida, dar resposta ao objetivo geral da investigação. Dos resultados obtidos, percebe-se que os diretores questionados consideram que possuem uma elevada inteligência emocional e fazem uso dela na sua atuação como diretores. Com estilos muitas vezes 
semelhantes, outras com alguns afastamentos, sentem que, diariamente, norteiam a sua ação usando as emoções como fundamento.

Em síntese, por tudo o que foi apresentado, predomina nos 3 grupos a consciência de que as características inerentes à inteligência emocional norteiam a ação do diretor de escola, nomeadamente no que diz respeito à preocupação em fazer mais e melhor na instituição. Questionados sobre esta competência, os grupos dos professores e dos assistentes operacionais apresentam uma elevada percentagem de respostas positivas, em concordância com as dos seus diretores. Outra competência que justifica a noção de que as características inerentes à inteligência emocional norteiam a ação do diretor de escola verifica-se no reconhecimento de que os líderes têm consciência das suas forças e limites, na medida em que a maioria dos liderados apresenta respostas afirmativas, com a maioria dos professores a salientar que quase sempre ou sempre possuem essa característica e a maioria dos assistentes operacionais a destacar a mesma opinião. A visão dos professores e dos assistentes operacionais confirma a dos diretores, quando confrontados com o facto de o diretor estar ausente quando precisam dele. Também o reconhecimento e satisfação das necessidades da comunidade educativa são avaliados de forma bastante positiva, mais uma vez em concordância com os diretores. Destaca-se que apenas o grupo dos professores considera que são reforçadas as vantagens de ter um sentido de missão comum na instituição. Os diretores respondem de forma positiva à ênfase que colocam nas vantagens referidas, posição concordante com a maioria dos professores.

No que diz respeito aos aspetos a melhorar na atuação dos diretores, começando pelas competências pessoais, dá-se especial destaque à reflexão que fazem sobre as críticas que lhes são feitas. De facto, os líderes assumem, na totalidade, que fazem sempre essa reflexão. Já os outros 2 grupos manifestam uma reduzida percentagem de concordância. Verifica-se uma discrepância igualmente acentuada no tocante à atuação do diretor apenas quando os problemas se tornam manifestos. Estes dizem que nunca o fazem, posição confirmada por uma percentagem reduzida de professores e de assistentes operacionais.

Passando às competências sociais, também se denotam divergências na certeza da liderança e motivação dos colaboradores para o sucesso, 
quando comparada a visão dos diretores com a dos restantes grupos. $\mathrm{Na}$ mesma orientação de análise está a questão "Ultrapassa os interesses pessoais em prol do grupo", com menos de metade dos professores e dos assistentes operacionais a afirmar que o fazem sempre.

Do exposto, pode depreender-se que possuir características de inteligência emocional é um fator essencial para uma gestão eficaz das organizações educativas ( Ruivo, 2015). Cooper (1997, citado por Zeidner et al., 2004) vem acrescentar que as pessoas com elevados níveis de inteligência emocional experienciam maior sucesso na carreira, conseguem relações interpessoais mais sólidas, têm um perfil mais adequado para a liderança e têm um funcionamento mais saudável do que pessoas com baixo nível de inteligência emocional.

\section{CONCLUSÃO}

A pesquisa bibliográfica que fundamentou o enquadramento teórico, coloca o indivíduo perante a necessidade de usar as suas emoções em toda e qualquer atuação, de forma a poder ser bem-sucedido. Os indivíduos emocionalmente inteligentes "são os que usam a razão para compreender as emoções (as suas e as dos outros) e lidar com elas, e que recorrem às emoções para interpretar a envolvente e tomar decisões mais inteligentes" (Cunha et al., 2010, p. 252). Contudo, Goleman (2002) argumenta ainda que o mundo tem ignorado um conjunto extremamente significativo de competências e habilidades que dizem respeito às pessoas e às emoções. De facto, Goleman e colaboradores (2002, p. 47) consideram que as emoções "são cruciais para a sobrevivência". Lopes e Baioa (2011) acrescentam, também, um bom nível de confiança na engrenagem de uma liderança bem sucedida.

Em Bar-On e Parker (2000) pode ler-se: "hoje em dia, os locais de trabalho consideram que a inteligência emocional é mais valiosa do que as competências técnicas e cognitivas" (p. 149). Lê-se ainda que, apesar de o conceito da inteligência emocional ser relativamente recente, "a preocupação em melhorar as competências sociais e emocionais nos locais de trabalho tem já uma grande história" (p. 149).

Salientam-se, assim, as principais conclusões deste estudo: 
- Relativamente ao perfil sociodemográfico da amostra, verifica-se que os três diretores exercem a função de direção há mais de dez anos.

- A maioria dos participantes dos grupos dos professores e assistentes operacionais são do género feminino.

- Verifica-se, ainda, que a grande maioria dos inquiridos do grupo de professores exerce funções há mais de vinte e cinco anos e pertence ao quadro das escolas onde trabalha, exercendo funções há mais de dezassete anos.

- A maioria dos sujeitos do grupo dos assistentes operacionais trabalha há mais de vinte anos, sendo do quadro de nomeação definitiva da escola há mais de treze.

- A maioria dos assistentes operacionais possui como habilitação o ensino secundário, existindo cinco com uma formação superior.

- Nas trinta e duas questões colocadas, os dois grupos (professores e assistentes operacionais) respondem maioritariamente em concordância com os seus diretores.

- No grupo dos assistentes operacionais, a maioria avalia negativamente o seu diretor nas questões "Reflete sobre as críticas que lhe são feitas e verifica se são ou não adequadas", "Reage de forma instintiva na resolução de problemas" e "Trata os outros como um indivíduo e não apenas como mais um membro do grupo".

- Na maior parte das questões, os grupos dos professores e dos assistentes operacionais apresentam um considerável número de respostas dentro de frequências pouco satisfatórias, não indo ao encontro da forma como os diretores se reconhecem.

Sabendo-se que não existem estudos perfeitos, encontraram-se algumas limitações neste estudo que poderão ser superadas em futuras investigações. Assim, destaca-se a fraca amplitude do conhecimento na área da Inteligência Emocional do diretor da escola, o que dificultou o desenvolvimento de todo o processo.

$\mathrm{Na}$ prática, as limitações prenderam-se com a aplicação dos questionários à totalidade dos professores e assistentes operacionais das escolas participantes. Na verdade, muitos dos docentes não responderam 
aos questionários por várias razões: por se encontrarem no final do ano letivo, com exames nacionais, avaliações e cansaço acumulado. Foi sentido outro constrangimento no facto de o objeto de estudo ser o diretor da própria escola onde professores e assistentes operacionais exerciam funções.

Assim, propõe-se uma amostragem maior e um alargamento da área geográfica de estudo, pois proporciona-se um maior alcance das conclusões retiradas e evita-se a concentração numa só área territorial, acautelando-se a influência nos resultados.

Considerando os resultados obtidos e a análise dos dados, pretendese deixar algumas recomendações que podem constituir contributos valiosos para e temática em estudo, no sentido de contribuírem para que a atuação do diretor de escola seja orientada por características de inteligência emocional que vão ao encontro das aspirações/desejos e expectativas do corpo docente e dos assistentes operacionais, contribuindo, assim, para a existência de uma escola de sucesso.

Deste modo, parece importante o desenvolvimento das seguintes ações:

\section{- Formação para os diretores}

A formação constitui um dos elementos do desenvolvimento pessoal e profissional. Assim, considera-se oportuna a frequência de formações na área da liderança e da gestão de conflitos, de forma a conseguir-se ultrapassar dificuldades que vão surgindo no desempenho do cargo, uma vez que o objetivo passa por encontrar ferramentas, mecanismos e estratégias que permitam lidar com o outro de forma a alcançar objetivos.

\section{- Criação de mecanismos de avaliação}

A auto e a heteroavaliação constituem pilares de extrema importância na melhoria da atuação de todos os profissionais. De forma a perceberem os pontos fracos, aos olhos dos professores e assistentes operacionais, sugere-se a criação de um mecanismo de avaliação da atuação do diretor. Dele, resultarão inevitavelmente os aspetos fortes e os pontos fracos/fragilidades da liderança. Assim, o diretor poderá melhorar o desempenho e ir ao encontro das expectativas dos seus 
colaboradores. Pensa-se que o processo de avaliação interna da escola deve ganhar contornos claros, transparentes e objetivos, e ser aplicado durante o mandato, a fim de evitar as perspetivas mais pessimistas apresentadas nas respostas dos intervenientes.

Também se sugerem encontros do diretor com os grupos intermédios, com o objetivo de avaliar as práticas de gestão e administração da escola.

\section{- Plano de formação da escola}

Os professores e os assistentes operacionais, enquanto agentes educativos, também serão sujeitos a formação nesta mesma linha de continuidade. Assim, para ambos, a formação em liderança emocional é uma condição essencial para o sucesso organizacional de uma escola. No grupo dos professores, e atendendo a que muitos destes desempenham cargos de lideranças intermédias, é importante monitorizar as suas práticas através de formação especializada e sugerese, igualmente, que as várias lideranças intermédias se encontrem sob a forma de workshop mensal, onde todos possam partilhar experiências, dificuldades e contributos.

\section{FONTES E BIBLIOGRAFIA}

Alarcão, I., \& Roldão, M. C. (2010). Supervisão Um contexto de desenvolvimento profissional dos professores. Mangualde: Edições Pedago, lda.

Álvarez, M. (2001). El Liderazgo de la Calida Total. Madrid: Editorial Praxis.

Afonso, N. (2005). Investigação Naturalista em Educação. Um Guia Prático e Crítico. Lisboa: Asa Editores.

Almeida, L. (1988). Teorias da Inteligência. Porto: Edições Jornal de Psicologia.

Almeida, L. S., Guisande, M. A., \& Ferreira, A. I. (2009). Inteligência Perspetiva Teóricas. Coimbra: Almedina.

Bar-on, R., \& Parker, J. (2000). The Handbook of Emotional Intelligence: Theory, Development, Assessment and Application at Home, School and in the Workplace, San Francisco: Jossey- Bass. 
Bergamini, C. (2009). Liderança: Administração do Sentido. S.Paulo: Edições S.Paulo.

Blanchard, K., Zigarmi, P. \& Zigarmi, D. (1992). O Líder um Minuto. Lisboa: Editorial

Presença.

Bolivar, A. (2003). Como Melhorar as Escolas: estratégias e dinâmicas de melhoria das práticas educativas. Porto: ASA.

Boyatzis, R. M. (2006). O Poder da Liderança Emocional. Rio de Janeiro: Elsivier Editora .

Bradberry Y, T., \& Greaves, J. (2008). Guia Prático da Inteligência Emocional. Lisboa: Bertrand Editora.

Brody, N. (2000). History of Theories and Measurements of Intelligence. In R.J. Sternberg (Ed.). Handbook of intelligence (pp. 16-33). Cambridge: Cambridge University Press.

Canavarro, J. (2000). Teorias e Paradigmas Organizacionais. Coimbra: Quarteto.

Cardoso, J. (2013). O Professor do Futuro. Lisboa: Guerra e Paz, Editores, S.A.

Carmo, H. (2008). Metodologia da Investigação. Guia para a Auto Aprendizagem. Lisboa: Universidade Aberta.

Caruso, David R., \& Salovey, Peter (1995), The Emotionally Intelligent Manager. How to develop and use the four key emotional skills of leadership, San Francisco: Jossey-Bass.

Coleman, J. S., Ernest, Q. C., Carol, J. H., McPartland, J., Mood, A., Weinfeld, F., \& York, R. (1966). Equality of educational opportunity. Washington: US Government Printing Office.

Chiavenato, I. (1999). Gestão de Pessoas: O Novo Papel dos Recursos Humanos nas Organizações. Rio de Janeiro: Elsevier.

Chiavenato, I. (2003). Administração nos Novos Tempos. Rio de Janeiro: Ed. Campus.

Cotovio, V. (2007). Procura de Si e Liderança. Lisboa: Editorial Caminho.

Coutinho, C. P. (2011). Metodologia de Investigação em Ciências Sociais e Humanas - Teoria e Prática. Lisboa: Edições Almedina.

Cunha, M \& Rego, A. (2005). Liderar. Lisboa: Publicações Dom Quixote. 
Cunha, M., Rego, A., Cunha, R., \& Cardoso, C. C. (2006). Manual de Comportamento Organizacional e Gestão. Lisboa: RH Editora.

Cunha, M., \& Rego, A. (2009). Liderança Positiva. Lisboa: Edições Sílabo.

Cunha, M., Rego, A., Cunha, R., Cabral- Cardoso, C., Marques, C. \& Gomes, J., (2010). Manual de Gestão de Pessoas e do Capital Humano. Lisboa: Edições Sílabo.

Damásio, A. (1995). O Erro de Descartes, Emoção, Razão e Cérebro Humano. Lisboa: Pb. Europa América.

Damásio, A. (2011), O Erro de Descartes. Emoção, Razão e Cérebro Humano. Lisboa: Temas e Debates.

Davies, M., Stankov, L., \& Roberts, R. D. (1998). Emotional intelligence: In search of an elusive construct. Journal of Personality and Social Psychology, 75 (4), 989-1015.

Dias, M. (2014). Ética, Organização e Valores em Contexto Organizacional. Revista Gestão e Desenvolvimento, 22, 89-113.

Donaldson-Feilder, E.J., \& Bond, F.W. (2004). The relative importance of psychological acceptance and emotional intelligence to workplace well-being. British Journal of Guidance \& Counselling, 32 (2), 187203.

Faria, L. (2007). Conceções Pessoais de Inteligência: Na Senda de um Modelo Organizador e Integrador no Domínio da Motivação. Revista de Psicologia da Vetor Editora, 8 (1), 13-20.

Feldman, R. S. (2001). Compreender a Psicologia. Amadora: McGrawHill.

Ferreira, R., Passos, C., Pereira, P. (2018). Motivação Organizacional: Fatores Percursores da Motivação do Colaborador. Revista Gestão e Desenvolvimento, 26, 107-133.

Filliozart, I. (1997). A Inteligência do Coração. Lisboa: Editora Pergaminho.

Fortin, M. (1999). O Processo de Investigação: da Concepção à Realização. Loures: Lusociência.

Fortin, M. (2009). Fundamentos e Etapas do Processo de Investigação. Lisboa:

Lusodidatica. 
Furnham, A. (2011). 50 Ideias de Psicologia que Precisa Mesmo de Saber. Alfragide: Publicações Dom Quixote.

Gallagher, E. N., \& Vella-Brodrick, D. A. (2008). Social Support and Emotional Intelligence as Predictors of Subjective Well-being. Personality and Individual Differences, 44, 1551-1561. doi:10.1016/j.paid.2008.01.011

Garcia, S. (2001). El Valor del Líder Postconvencional: la Gestióndelmiedo. In: LIDERANDO con emoción. Madrid: Soluziona-GriekerOrgemer, Disponível em: <http:// www.managementbyvalues.com/ docs/pdf» acesso em: $05 \mathrm{dez} 2015$.

Gardner, H. (1983). Frames of Mind. The Theory of Multiple Intelligences. Nova Iorque: Basic Books.

Gardner, H. (1999). Intelligence Reframed: Multiple intelligences for the 21 st century. Nova Iorque: Basic Books.

Garrido, M. P., \& Pacheco, N. E. (2012). Inteligencia emocional percibida en el profesorado de primaria y su relación con los niveles de burnout e ilusión por el trabajo (engagement). Revista de Educación, 359, 604-627. doi:10.4438/1988-592X-RE-2011-359109.

George, J. (2000). Emotions and Leadership: The Role of Emotional Intelligence. Human Relations.

Goleman, D. (1995). Inteligência Emocional. Lisboa: Temas e Debates.

Goleman, D. (1997), Inteligência Emocional, Lisboa: Temas e Debates.

Goleman, D. (1999). Inteligência Emocional. Lisboa: Temas e Debates.

Goleman, D. (1998). What Makes a Leader?, Harvard Business Review, 76, Boston: HBS Publishing Corporation, pp. 93-102.

Goleman, D. (2000). Trabalhar com Inteligência Emocional. Lisboa: Temas e Debates.

Goleman, D. (2002). Inteligência Emocional. Lisboa: Temas e Debates.

Goleman, D. (2010). Inteligência Emocional. Lisboa: Círculo de Leitores.

Goleman, D., Boyatzis, R., \& Mckee, A. (2002). Os Novos Líderes: a Inteligência Emocional nas Organizações. Lisboa: Gradiva.

Goleman, D., Boyatzis, R., \& Mckee, A. (2003). Os Novos Líderes. Lisboa: Gradiva. 
Goleman, D., Boyatzis, R., \& Mckee, A. (2007). Os Novos Lideres. A Inteligência Emocional nas Organizações. Lisboa: Gradiva.

Jesuíno, J. (1996). Processos de Liderança (2. ${ }^{\text {a }}$ ed.). Lisboa: Editorial Livros Horizonte.

Ledoux, J. (2000). O Cérebro Emocional. Lisboa: Pergaminho.

Lima, J. (2008). Em Busca da Boa Escola. Vila Nova de Gaia: Fundação Manuel Leão.

Lopes, P.N., Grewal, D., Kadis, J., Gall, M., \& Salovey, P. (2006). Evidence that emotional intelligence is related to job performance and affect and attitudes at work. Psicothema, 18, 132-138.

Lopes, A., Baioa, P. (2011). O Impacto da Liderança Partilhada no Desempenho Organizacional Percecionado. Revista Gestão $e$ Desenvolvimento, 19, 7-36.

MacBeath, J., Schratz, M., Meuret, D., \& Jakobsen, L. B. (2005). A Hstória de Serena. Viajando Rumo a Uma Escola Melhor. Porto: Edições Asa.

Madsen, S. R. \& Hammond, S. (2005). Where have all the leaders gone? An interview with Margaret J. Wheatley about life-affirming leadership. Journal of Management Inquiry, 14 (1), 71-77.

Mayer, J. D., \& Salovey, P. (1993). The Intelligence of Emotional Intelligence. Intelligence, 17, 433-442.

Meyer, M. (1994). O Filósofo e as Paixões. Porto: Edições Asa.

Miville, M.L., Carlozzi, A.F., Gushue, G.V., Schara, S.L \& Ueda, M. (2006). Mental health counsellor qualities for a diverse clientele: linking empathy, universal-diverse orientation, and emotional intelligence. Journal of mental health counselling, 28 (2), 151-165.

Nikolaou, I. \& Tsaousis, I. (2002). Emotional Intelligence in the workplace: exploring its effects on occupational stress and organizational commitment. The International Journal of Organizational Analysis, 10 (4), 327-342.

Novak, J. D. (2000). Apreender Cria e Utilizar o Conhecimento. Lisboa: Plátano Edições Técnicas.

O'Boyle, E. H., Humphrey, R. H., Pollack, J. M., Hawver, T. H., \& Story, P. A. (2011). The relation between emotional intelligence and job performance: A meta-analysis. Journal of Organizational Behavior, 32, 788-818. doi:10.1002/job.714. 
Quivy, L.V.C. (2005). Manual de Investigação em Ciências Sociais. Lisboa: Gravida.

Reale, G. (1994). As ciências práticas: ética e política, in História da Filosofia Antiga. (Trad. italiano: Henrique Claúdio de Lima Vaz e Marcelo Perine). Vol II, São Paulo, Loyola.

Rego, A. (1998), Liderança nas Organizações - Teoria e Prática. Aveiro: Universidade de Aveiro.

Rebelo, M. C. A. (2011). Concepções e práticas de professores do $2^{\circ}$ e $3^{o}$ ciclo do Ensino Básico face à Inclusão de Crianças com Necessidades educativas Especiais (Dissertação de Mestrado não publicada). Escola Superior de Educação de Lisboa, Lisboa.

Rebelo, A., Martins, R. (2015). Inteligência Emocional dos Profissionais de Saúde da Rede de Cuidados Continuados Integrados. Revista Gestão e Desenvolvimento,23, 67-84.

Ruivo, J., \& Rebelo, S. (2014). A Inteligência Emocional na Gestão das Instituições Educativas em Portugal. Campo Abierto, 33 (1), 137-150

Ruivo, J., \& Paes, S. (2015). Inteligência Emocional e Liderança Escolar. Aula, Revista de Pedagogia da Universidade de Salamaca, 21, 233-244.

Sanches, M. F. C. (1998). Para uma Compreensão Democrática da Liderança Escolar: Da Concepção Hierárquica e Racional à Concepção Participatória e Colegial. Revista de Educação, VII (1), 49-63.

Snarey, J.R. \& Vaillant, G.E. (1985). How Lower- and Working Class Youth Become Middleclass Adults: the Association Between Ego Defense Mechanisms and Upward Social Mobility. Child development, 56 (4), 899-910.

Sternberg, R. J. (1999). Successful intelligence: finding a balance. Trends in Cognitive Sciences, 3 (11), 436-442.

Sternberg, R.J. (2000). The concept of intelligence. Em R. J. Sternberg (Ed Handbook of intelligence.).

Trigo, J., \& Costa, A. (2008). Liderança nas Organizações Educativas: a Direcção por Valores. Ensaio Avaliação e Políticas Educativas, 16 (61), 561-582.

Trivellasa, P., Gerogiannisb, V., \& Svarnab, S. (2013). Exploring Workplace Implications of Emotional Intelligence (WLEIS) in 
Hospitals: Job Satisfaction and Turnover Intentions. Procedia Social and Behavioral Sciences, 73, 701-709. doi:10.1016/j.sbspro.2013.02.108

Tuckman, B. (2000). Manual de Investigação em Educação. Lisboa: Fundação Calouste Gulbenkian.

Wall, Bob (2007). Working Relationships: Using Emotional Intelligence to enhance your effectiveness with others, California: Davies - Black Publishing

Zee, K., Thijs,M., \& Schakel,L. (2002) The Relationship of Emotional Intelligence With Academic Intelligence and the Big Five. European Journal of Personality, 16, 103-125.

Zeidner, M., Matthews, G., \& Roberts, R.D. (2004) Emotional Intelligence in the workplace: a critical review. Applied Psychology:an International Review, 53 (3), 371-399.

\section{Legislação}

Decreto-Lei n. ${ }^{\circ} 137 / 2012$ de 2 de Julho.

Decreto-lei $n^{\circ} 75 / 2008$.

Decreto-Lei n. ${ }^{\circ} 115-\mathrm{A} / 98$, de 4 de maio.

Decreto-Lei n. ${ }^{\circ} 172 / 91$, de 10 de maio.

Decreto-Lei n. ${ }^{\circ}$ 43/89, de 3 de fevereiro.

Decreto-Lei n. ${ }^{\circ} 769-\mathrm{A} / 76$, de 23 de outubro.

Lei n. ${ }^{\circ} 46 / 86$, de 14 de outubro. 